\title{
Micro and Nano Engineered High Volume Ultrafine Fly Ash Cement Composite with and without Additives
}

\author{
R. Roychand*, S. De Silva, D. Law, and S. Setunge
}

(Received July 14, 2015, Accepted December 20, 2015, Published online January 11, 2016)

\begin{abstract}
This paper presents the effect of silica fume and nano silica, used individually and in combination with the set accelerator and/or hydrated lime, on the properties of class F high volume ultra fine fly ash (HV-UFFA) cement composites, replacing $80 \%$ of cement (OPC). Compressive strength test along with thermogravimetric analysis, X-ray diffraction and scanning electron microscopy were undertaken to study the effect of various elements on the physico-chemical behaviour of the blended composites. The results show that silica fume when used in combination with the set accelerator and hydrated lime in HV-UFFA cement mortar, improves its 7 and 28 day strength by 273 and $413 \%$, respectively, compared to the binary blended cement fly ash mortar. On the contrary, when nano silica is used in combination with set accelerator and hydrated lime in HV-UFFA cement mortar, the disjoining pressure in conjunction with the self-desiccation effect induces high early age micro cracking, resulting in hindering the development of compressive strength. However, when nano silica is used without the additives, it improves the 7 and 28 day strengths of HV-UFFA cement mortar by 918 and $567 \%$, respectively and the compressive strengths are comparable to that of OPC.
\end{abstract}

Keywords: nano silica, silica fume, fly ash, additives, X-ray diffraction, scanning electron microscopy.

\section{Introduction}

Globally, out of the total fly ash (FA) production of 620-660 Million tons per year, only about $53.5 \%$ is currently being utilized and the remaining forms part of the landfills (Heidrich et al. 2013). FA producers have to spend large amount of money for the safe disposal of this unutilized industrial by product (About Coal Ash-CCP FAQs. American Coal Ash Association 2014). This poses a big challenge to both the fly ash producers and the research community, to bring down this production vs utilization ratio to a minimum possible level.

FA has good pozzolanic properties and it can be used as a supplementary cementitious material (SCM). In addition, the production of cement (OPC) is responsible for 5-7\% of global greenhouse gas emissions (Benhelal et al. 2013). Therefore, using fly ash as a cement replacement material provides dual benefit (i) it helps in increasing the use of this industrial by product and (ii) it assists in cutting down the emissions associated with the cement production. Moreover, it not only enhances the properties of fresh concrete like workability (Sata et al. 2007; Liu 2010) but also improves its

School of Civil, Environmental and Chemical

Engineering, RMIT University, Melbourne, VIC,

Australia.

*Corresponding Author;

E-mail: rajeev.roychand@rmit.edu.au

Copyright $($ The Author(s) 2016. This article is published with open access at Springerlink.com mechanical and durability properties such as; greater long term strength (Hansen 1990; Sivasundaram et al. 1990), lower shrinkage (Atis 2003; Nakarai and Ishida 2008), lower water absorption (Malhotra and Mehta 2002; Şahmaran et al. 2009), reduction in chloride permeability (Nagataki and Ohga 1992; Dinakar et al. 2008), increased resistance to sulphate attack (Structure et al. 1986; Turanli et al. 2005), low heat of hydration (Turanli et al. 2005; Kasai et al. 1983) and reduction in alkali aggregate reactivity (Turanli et al. 2005; Pepper and Mather 1959; Islam 2014). Although fly ash has many advantages when used as a cement replacement material, it has one major disadvantage of low reactivity (Liu 2010; Şahmaran et al. 2009). Therefore, it has to be a very judicious decision to choose a percentage of fly ash content as cement replacement material in a mix design. Numerous research studies have been conducted in the past to address its low reactivity and to improve the strength of fly ash blended mixes. Researchers have looked at the effect of particle size (Paya et al. 1995; Chindaprasirt et al. 2005), use of hydrated lime (Şahmaran et al. 2009; Barbhuiya et al. 2009), silica fume (Barbhuiya et al. 2009; Sellevold and Radjy 1983; El-Chabib and Syed 2012; Rashad 2014), metakaolin (Wei et al. 2007; Reis and Camões 2011) to improve the mechanical properties of fly ash blended mixes.

Paya et al. (1995) investigated the effect of reduction in particle size on the reactivity of fly ash blended cement concrete. They found that a linear relation between the particle size and compressive strength exists in fly ash blended concrete. Compressive strength of fly ash concrete increased with the decrease in its particle size (Paya et al. 
1995; Chindaprasirt et al. 2005; Erdoğdu and Türker 1998; $\mathrm{Li}$ and $\mathrm{Wu}$ 2005). Hill et al. (1994) studied the effect of calcium nitrate set accelerator (SA) on the hydration reaction of fly ash. They found that calcium nitrate considerably accelerated the hydration reaction of fly ash resulting in the improvement in its setting time and compressive strength. Studies show that hydrated lime (HL) considerably improves the reactivity of fly ash. It accelerates the hydration reaction resulting in a significant improvement of compressive strength of high volume fly ash (HVFA) concrete (Barbhuiya et al. 2009; Jayakumar and Abdullahi 2011). Bharbhuia et al. (Barbhuiya et al. 2009) and Rashad et al. (2014) studied the effect of silica fume (SF) on the mechanical properties of HVFA concrete. They found that addition of silica fume considerably improved the 7 and 28 day strength. Moreover, Silica fume performed considerably better than hydrated lime in improving the early age strength of fly ash concrete (Barbhuiya et al. 2009).

Recently, amorphous nano silica (nS) has been gaining widespread attention of the research community due to its nano sized particles and very high amorphous $\mathrm{SiO}_{2}$ content (Björnström et al. 2004; Jo et al. 2007; Zhang and Islam 2012; Hou et al. 2012; Singh et al. 2015). It not only takes part in the hydration reaction to provide additional $\mathrm{C}-\mathrm{S}-\mathrm{H}$ but also accelerates the hydration process (Björnström et al. 2004; Zhang and Islam 2012; Hou et al. 2012). Hou et al. (Hou et al. 2012) investigated the effect of $0,2.25$ and $5 \%$ colloidal nano silica (CNS) on $60 \%$ FA blended cement composite. They found that the compressive strength of the mortar samples at 7 and 28 days increased with the increasing amount of CNS but at 3 months no significant difference in their respective strength results was observed. The maximum increase in strength that they observed with $5 \% \mathrm{CNS}$ compared to $0 \% \mathrm{CNS}$ at 7 and 28 days was approximately 60 and $33 \%$ respectively. Shaikh et al. (Shaikh et al. 2014) studied the effect of $2 \%$ nano silica on $68 \%$ FA blended cement composite and found that there was no difference in strength at 7 days but at 28 days there was $56 \%$ increase in strength as compared to the mix not containing nano silica.

Based on the review of past literature there appears to be limited or no research available on the effect of silica fume and nano silica in combination with hydrated lime and set accelerator on the properties of class $\mathrm{F}$ high volume fly ash (HVFA) cement composite. In addition, a significant variation in the effect of nano silica on the percentage of strength improvement of high volume fly ash cement composites has been observed (Zhang and Islam 2012; Hou et al. 2012; Shaikh et al. 2014). Very few studies are available that report the properties of class $\mathrm{F}$ high volume fly ash cement composite replacing $80 \%$ of cement (Liu 2010; Huang et al. 2013). With the successful replacement of $80 \%$ cement with supplementary cementitious materials, predominantly containing fly ash, the cement industry could benefit in significantly reducing its $\mathrm{CO}_{2}$ emissions, and at the same time the production/utilisation rate of fly ash could be reduced. Therefore this study was undertaken to investigate the effect of $\mathrm{SF}$ and $\mathrm{nS}$ in combination with $\mathrm{HL}$ and $\mathrm{SA}$ on the physico-chemical behaviour of class $\mathrm{F}$ high volume ultrafine fly ash (HV-UFFA) cement composite, replacing $80 \%$ of cement. Compressive strength test has been undertaken to identify the mechanical properties of the blended mortar samples. In addition, thermogravimetric analysis (TGA), X-ray diffraction (XRD) and secondary electron microscopy (SEM) have been undertaken to identify the formation of various hydrates and to understand the morphological changes occuring in the cement matrix due to the addition of various materials under study.

\section{Materials and Experimental Procedure}

\subsection{Materials and Mix Design}

The materials used in this study were: Ordinary portland cement, non-chloride calcium nitrate and sodium thiocyanate based set accelerator "Pozzolith NC 534" having water content of $51 \%$ and polycarboxylic ether based superplasticizer "Glenium 79" having water content of $55 \%$, class F low calcium ultra fine fly ash, hydrated lime, densified silica fume (SF) and powdered nano silica. Raw fly Ash having a mean particle size of $15 \mu \mathrm{m}$ was ground in a micronizer to produce ultrafine fly ash (UFFA) of mean particle size of $8.1 \mu \mathrm{m}$. Chemical composition of OPC, FA, SF, HL and $\mathrm{nS}$ is presented in Table 1. Particle size distribution of OPC, UFFA, HL, and SF was obtained by using laser diffraction particle size analyser "Malvern Mastersizer 3000" and is presented in Table 2.

XRD spectra of OPC, HL, FA, SF and $\mathrm{nS}$ are shown in Fig. 1. Predominant crystalline content of $\mathrm{OPC}$ are calcium silicates $\left(\mathrm{C}_{2} \mathrm{~S}, \mathrm{C}_{3} \mathrm{~S}\right)$, calcium aluminate $\left(\mathrm{C}_{3} \mathrm{~A}\right)$, calcium alumino ferrite $\left(\mathrm{C}_{4} \mathrm{AF}\right)$ and gypsum $(\mathrm{G})$. Hydrated lime shows a sharp calcite peak at $29.4^{\circ} 2$-theta in addition to $\mathrm{Ca}(\mathrm{OH})_{2}$ peaks. The crystalline content in FA was mainly from quartz and mullite. SF and $\mathrm{nS}$ shows broad peaks centred around $22^{\circ}$ and $22.5^{\circ}$ 2-theta respectively, which is a typical characteristic of amorphous silica content.

Table 3 summarizes the various mortar mix designs tested. All binding materials used were based on percentage mass of the total binding material. TGA, XRD and SEM samples were prepared with the binder paste only. Amount of superplasticizer was adjusted to get an approximately similar consistency for the self consolidation of the mortar. Water content of SP and SA were included in the total $\mathrm{w} / \mathrm{b}$ ratio.

\subsection{Sample Preparation, Curing \& Testing 2.2.1 Compressive Strength of Mortar}

All the raw materials were dry mixed at low speed in the mortar mixer for $1 \mathrm{~min}$ to obtain a homogenous mix. Then water, SP and SA (as required) were added and mixed for 3 min, followed by a final high speed mixing for another $1 \mathrm{~min}$. Mortar samples were then poured in $50 \mathrm{~mm} \times 50 \mathrm{~mm} \times 50 \mathrm{~mm}$ steel moulds. The samples were covered with a plastic sheet, cured in room temperature for $24 \mathrm{~h}$, de-moulded (except CF and S1 which were demoulded after $48 \mathrm{~h}$ and $36 \mathrm{~h}$ respectively, because of low early strength) and then further cured in saturated lime water 
Table 1 Chemical composition of OPC, HL, FA, SF and nS.

\begin{tabular}{|c|c|c|c|c|c|}
\hline Materials & OPC (\%) & HL (\%) & FA (\%) & SF (\%) & NS (\%) \\
\hline $\mathrm{SiO}_{2}$ & 22.3 & 1.5 & 73.1 & 88.2 & 99.9 \\
\hline $\mathrm{Al}_{2} \mathrm{O}_{3}$ & 5.2 & 0.6 & 22.8 & 1.2 & - \\
\hline $\mathrm{Fe}_{2} \mathrm{O}_{3}$ & 0.7 & 0.3 & 0.8 & 2.16 & - \\
\hline $\mathrm{CaO}$ & 63.9 & 73.7 & 0.1 & 1.16 & - \\
\hline $\mathrm{SO}_{3}$ & 2.7 & - & 0.1 & 1.67 & - \\
\hline $\mathrm{MgO}$ & 1.2 & 0.5 & 0.2 & 1.57 & - \\
\hline $\mathrm{Na}_{2} \mathrm{O}$ & 0.1 & 0.16 & 0.01 & 0.11 & - \\
\hline $\mathrm{K}_{2} \mathrm{O}$ & 0.2 & 0.07 & 0.58 & 0.23 & - \\
\hline $\mathrm{TiO}_{2}$ & - & - & 1.4 & - & - \\
\hline $\mathrm{P}_{2} \mathrm{O}_{5}$ & - & - & 0.1 & 1.02 & - \\
\hline $\mathrm{Mn}_{2} \mathrm{O}_{3}$ & - & - & 0.04 & 0.14 & - \\
\hline LOI & 3.9 & 24.1 & 0.8 & 2.8 & - \\
\hline
\end{tabular}

Table 2 Particle size distribution of OPC, UFFA, RHL, HL, SF and NS.

\begin{tabular}{c|c|c|c|c|c|c}
\hline Material & Mean $(\mu \mathrm{m})$ & $d_{10}(\mu \mathrm{m})$ & $D_{25}(\mu \mathrm{m})$ & $D_{50}(\mu \mathrm{m})$ & $D_{75}(\mu \mathrm{m})$ & $D_{90}(\mu \mathrm{m})$ \\
\hline \hline OPC & 24.6 & 2.7 & 6.5 & 15.4 & 28.3 & 44.2 \\
\hline UFFA & 8.1 & 1.2 & 1.2 & 4.6 & 9.2 & 15.0 \\
\hline HL & 8.2 & 0.9 & 2.1 & 4.3 & 8.6 & 19.4 \\
\hline SF & 3.0 & 0.3 & 0.5 & 1.4 & 3.9 & 8.1 \\
\hline NS* & $7 \mathrm{~nm}$ & - & - & - & - & - \\
\hline
\end{tabular}

* Particle size of nano silica (nS) is shown in nano meters.

at room temperature as per ASTM C109 until the time of testing. The samples were taken out of lime water, wiped and surface dried after 1, 7 and 28 days of curing. Compressive strength of the mortar samples was measured as per ASTM C109 using a $300 \mathrm{kN}$ tecnotest mortar strength testing machine. For every mix at each age, three replicates were tested at a loading rate of $0.36 \mathrm{MPa} / \mathrm{s}$.

\subsubsection{TGA, XRD and SEM of Hardened Binder Paste}

Mixing procedure and curing method was kept the same for TGA, XRD and SEM binder paste samples. For TGA and $\mathrm{XRD}$, the samples were ground and sieved through $63 \mu \mathrm{m}$ sieve. To stop hydration and to remove physically bound water the solvent exchange method was adopted using acetone. A $100 \mathrm{~mL}$ of acetone was added to $30 \mathrm{~g}$ of the sieved sample in a plastic bottle and mixed vigorously by hand for about $3 \mathrm{~min}$. Excess acetone was drained out and the process was repeated. The samples were then dried overnight in an oven at $40{ }^{\circ} \mathrm{C}$ temperature. The dried samples were collected and stored in a sealed plastic container till the time of testing.

TGA was conducted using PerkinElmer STA 6000 thermal analyser in a nitrogen environment with a flow rate of $19.8 \mathrm{~mL} \mathrm{~min}^{-1}$. $10-20 \mathrm{mg}$ of powdered samples were heated from 40 to $550{ }^{\circ} \mathrm{C}$ with the heating rate of $10{ }^{\circ} \mathrm{C}$ $\min ^{-1}$.

XRD was conducted using a Bruker AXS D4 Endeavour system using $\mathrm{Cu}-\mathrm{K} \alpha$ radiation operated at $40 \mathrm{kV}$ and $40 \mathrm{~mA}$ and a Lynxeye linear strip detector. Samples were tested between $5^{\circ}$ and $55^{\circ} 2$-theta $(2 \theta)$ with a step size of $0.02^{\circ}$ and the counting time per step was $5 \mathrm{~s}$.

For SEM, a small thin section of the hardened paste was cut out from the internal part of the specimen. It was then embedded in epoxy, ground, polished, mounted on a steel stub and gold coated. FEI Quanta 200 SEM was used to study the microstructure of the hardened paste samples. The accelerating voltage of the beam was $20 \mathrm{kV}$ and the electron images were acquired at $10 \mathrm{~mm}$ working distance and $5000 \times$ magnification.

\section{Results and Discussion}

\subsection{Compressive Strength}

The effect of silica fume, set accelerator and hydrated lime on HV-UFFA mortar is shown in Fig. 2a. By partially replacing UFFA with SF, there was a $55 \%$ increase in 7 day strength which further increased to $116 \%$ at 28 days in S1 compared to that of CF. This is attributed to the effect of SF on the 

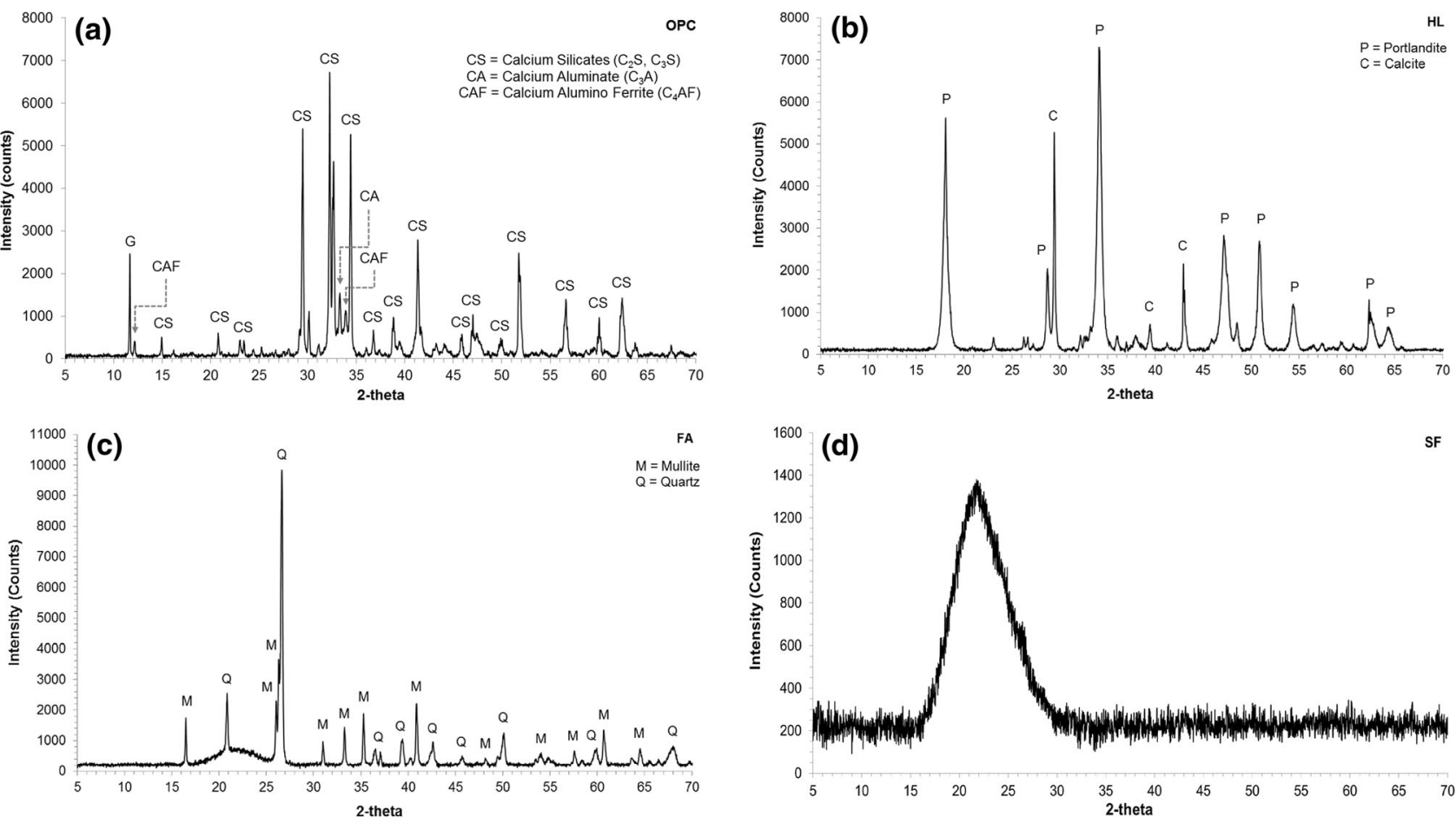

(d)

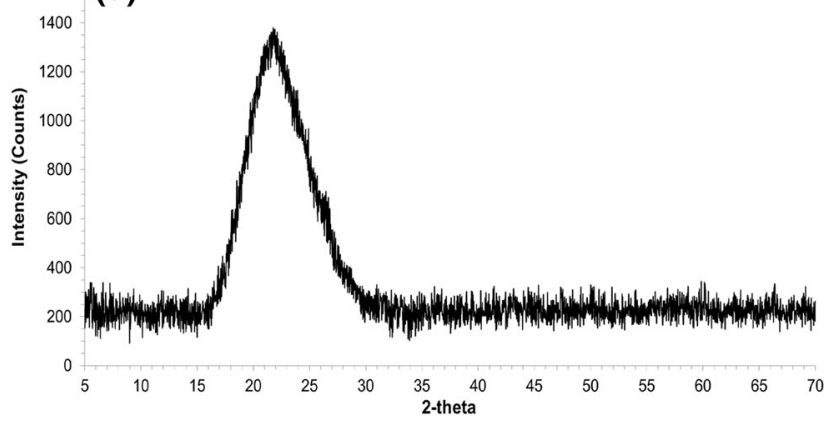

(e)

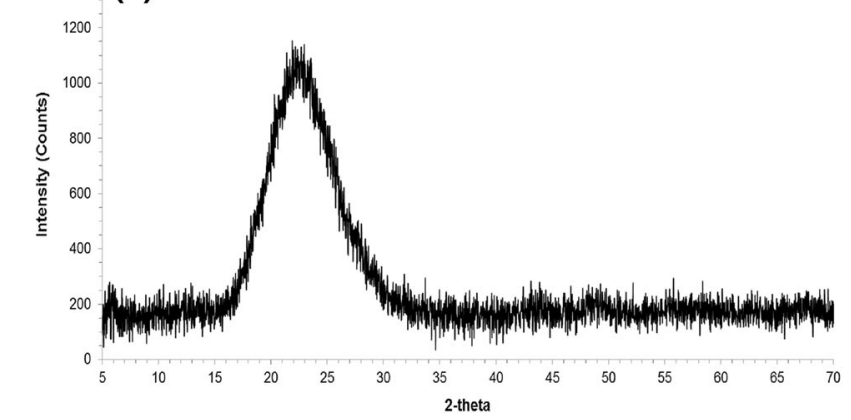

Fig. 1 XRD spectra of a OPC, b HL, c FA, d SF and e NS.

Table 3 Mortar mix designs.

\begin{tabular}{|c|c|c|c|c|c|c|c|c|c|}
\hline \multirow[t]{2}{*}{ Mix } & \multicolumn{5}{|c|}{ Total Binder } & \multirow[t]{2}{*}{$\mathrm{S} / \mathrm{B}$} & \multirow[t]{2}{*}{$\mathrm{W} / \mathrm{B}$} & \multirow[t]{2}{*}{ SP } & \multirow[t]{2}{*}{ SA } \\
\hline & OPC (\%) & UFFA & $\mathrm{HL}$ & SF & NS & & & & \\
\hline Control & 100 & - & - & - & - & 2.4 & 0.3 & 27.5 & - \\
\hline $\mathrm{CF}$ & 20 & $80 \%$ & - & - & - & 2.4 & 0.3 & 11.5 & - \\
\hline S1 & 20 & $65 \%$ & - & $15 \%$ & - & 2.4 & 0.3 & 30.0 & - \\
\hline S2 & 20 & $65 \%$ & - & $15 \%$ & - & 2.4 & 0.3 & 30.0 & 27.5 \\
\hline S3 & 20 & $60 \%$ & $5 \%$ & $15 \%$ & - & 2.4 & 0.3 & 30.0 & - \\
\hline $\mathrm{S} 4$ & 20 & $60 \%$ & $5 \%$ & $15 \%$ & - & 2.4 & 0.3 & 30.0 & 27.5 \\
\hline N1 & 20 & $75 \%$ & - & - & $5 \%$ & 2.4 & 0.3 & 60.0 & - \\
\hline $\mathrm{N} 2$ & 20 & $75 \%$ & - & - & $5 \%$ & 2.4 & 0.3 & 60.0 & 27.5 \\
\hline N3 & 20 & $70 \%$ & $5 \%$ & - & $5 \%$ & 2.4 & 0.3 & 60.0 & - \\
\hline N4 & 20 & $70 \%$ & $5 \%$ & - & $5 \%$ & 2.4 & 0.3 & 60.0 & 27.5 \\
\hline
\end{tabular}

$S / B$ sand/binder ratio, $W / B$ water/binder ratio, $S P$ superplasticizer $=\mathrm{mL} \mathrm{kg}^{-1}$ binder, $S A$ set Accelerator $=\mathrm{mL} \mathrm{kg}^{-1}$ binder.

improvement of strength of HVFA cement composite. Silica fume, because of its amorphous character and large surface area, possesses high pozzolanic activity and readily reacts with the available $\mathrm{Ca}(\mathrm{OH})_{2}$ to form additional calcium silicate hydrate, resulting in the improvement of strength. Similar results have been reported by Barbhuiya et al. (Barbhuiya et al. 2009). With 

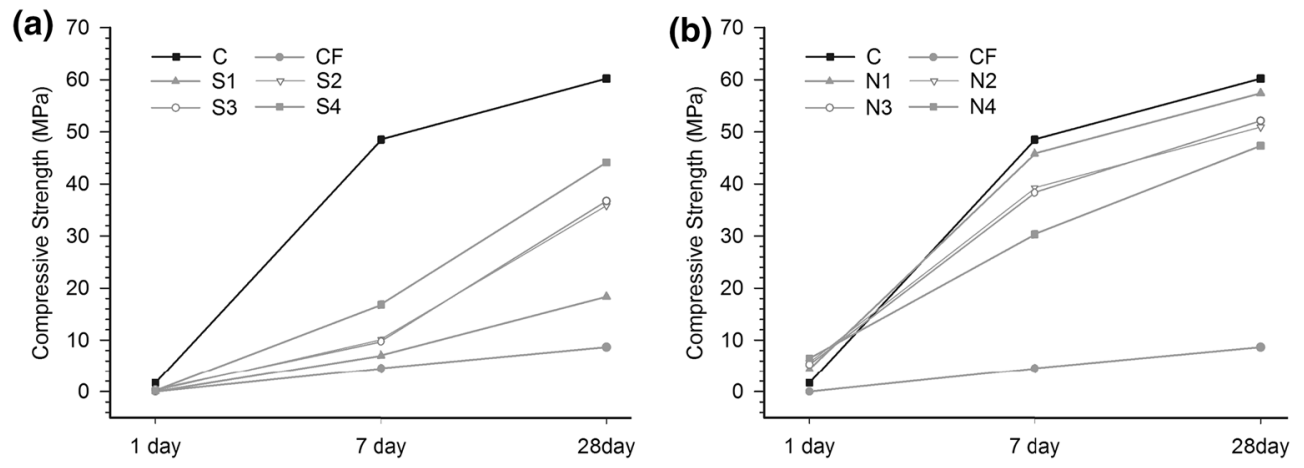

Fig. 2 Compressive strength of mortar samples (a) containing silica fume (b) containing nano silica at $1,7 \& 28$ days of curing.

the combination of silica fume and set accelerator in Mix S2, the 7 and 28 day strengths improved by 124 and $316 \%$ respectively, compared to that of Mix CF. This is attributed to the accelerating effect of SA on the pozzolanic reaction of the blended mix, which is discussed in detail in Sect. 3.2. By combining silica fume and hydrated lime in mix S3, the strength improvement was approximately the same as that of S2. The performance of $5 \%$ hydrated lime addition was equivalent to that of set accelerator with $27.5 \mathrm{~mL} \mathrm{~kg}^{-1}$ binder content in improving the compressive strength of silica fume modifed $\mathrm{HV}$ UFFA cement composite. When both SA and HL were added to the silica fume modified HV-UFFA in Mix S4, the 7 and 28 day strengths were improved by 273 and $413 \%$ respectively. The combined acceleration effect imparted by SA and HL significantly improved the compressive strength of S4 compared to that of CF. This shows that the performance of the combined effect of SF, SA and HL is significantly higher than that of their individual additions in improving the compressive strength of HV-UFFA cement composite.

Figure $2 \mathrm{~b}$ demonstrates the effect of nano silica, set accelerator and hydrated lime on HV-UFFA mortar. By partially replacing UFFA with $\mathrm{nS}$, there was a significant improvement in 1 day strength of mix N1 compared to that of CF and the 7 and 28 day strengths increased by 918 and $567 \%$ respectively. This significant improvement in strength is attributed to the amorphous character and very high surface area of nano silica, which readily reacts with the available $\mathrm{Ca}(\mathrm{OH})_{2}$ to form additional calcium silicate hydrate. Comparing the effect of silica fume in S1 to that of nano silica in N1, nano silica performed significantly better than silica fume in improving the compressive strength. Though, both $\mathrm{SF}$ and $\mathrm{nS}$ are amorphous in nature but the particle size of nano silica is approximately 425 times smaller than the average particle size of SF. This extremely small particle size of nano silica provides a very high surface area, that accelerates the pozzolanic reaction resulting in much higher compressive strength than that with SF. When set accelerator was combined with nano silica in Mix N2, there was a further $30 \%$ improvement in one day strength, but the 7 and 28 day strengths decreased by approximately 14 and $11 \%$ respectively, compared to N1. This shows that though set accelerator improves the pozzolanic reaction, which results in higher 1 day strength, it has a negative impact at 7 and 28 day strengths. In comparison, the set accelerator had positive impact on silica fume modified HV-UFFA at all ages. By combining nano silica and hydrated lime in mix N3, the strength improvement was approximately the same as that of N2. Similarly, no difference on the treatment of SA and HL was observed on silica fume modified HV-UFFA mixes $\mathrm{S} 2$ and $\mathrm{S} 3$. When both SA and HL were added to the nano silica modified HV-UFFA in Mix S4, though the 1 day strength improved by $48 \%$, the 7 and 28 day strengths decreased by 34 and $18 \%$ respectively. The combined effect of SA and HL was positive at 1 day and was higher than that of their individual effects. But at 7 and 28 days the combination of SA and HL proved detrimental to the strength development of HV-UFFA modified with $\mathrm{nS}$ and was worse than that of their individual effects.

\subsection{TGA, XRD and SEM Analysis}

Derivative thermogravimetric (DTG) curves were plotted from the thermogravimetric (TG) data to identify the exact boundaries of the Calcium hydroxide $(\mathrm{CH})$ content at various ages of curing. Figure 3 a shows typical TG and DTG curves with identifiable $\mathrm{CH}$ endotherm. The onset and the endset point of $\mathrm{CH}$ mass loss identified with the help of derivative curve, has been marked with dotted lines. Figure $3 \mathrm{~b}$ shows a typical TG and DTG curves with no identifiable $\mathrm{CH}$ endotherm. The absence of $\mathrm{CH}$ endothermic peak shows that the residual $\mathrm{CH}$ content, at a particular age of curing was too small (if any) to be detected with the help of TGA.

$\mathrm{CH}$ (residual) in Eq. (1) represents the residual $\mathrm{CH}$ content at a particular age of curing, expressed in percentage of the mass of dry sample at $500{ }^{\circ} \mathrm{C}\left(\mathrm{M}_{500}\right)$ (De Weerdt et al. 2011). $\mathrm{CH}$ (normalised) in Eq. (2) denotes the normalised $\mathrm{CH}$ content per $\mathrm{g}$ of cement, in which no hydrated lime powder has been added. $\mathrm{CH}$ (normalised) in Eq. (3) was modified to suit the addition of hydrated lime powder.

$$
\begin{aligned}
& \mathrm{CH}(\text { residual })=\frac{\mathrm{M}_{\mathrm{H}_{2} \mathrm{O} \mathrm{CH}}^{\mathrm{S}} * \frac{74}{18}}{\mathrm{M}_{500}} * 100[\%] \\
& \mathrm{CH} \text { (normalised) }=\frac{\mathrm{M}_{\mathrm{H}_{2} \mathrm{O} \mathrm{CH}}^{\mathrm{S}} * \frac{74}{18}}{\mathrm{M}_{500}} * \frac{1}{0.2} * 100[\%]
\end{aligned}
$$

(without additional hydrated lime)

$$
\begin{aligned}
& \mathrm{CH} \text { (normalised) } \\
& =\frac{\left[\left\{\mathrm{M}_{\mathrm{H}_{2} \mathrm{O} \mathrm{CH}}^{\mathrm{S}} * \frac{74}{18}\right\}-\left\{\left(\mathrm{M}_{\mathrm{H}_{2} \mathrm{O} \mathrm{CH}}^{\mathrm{HL}} * \frac{74}{18}\right) * \mathrm{HL} \%\right\}\right]}{\mathrm{M}_{500}} \\
& \quad * \frac{1}{0.2} * 100[\%]
\end{aligned}
$$

(with additional hydrated lime) 
(a)

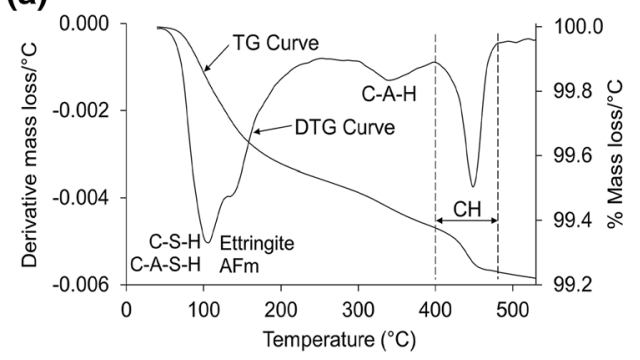

(b)

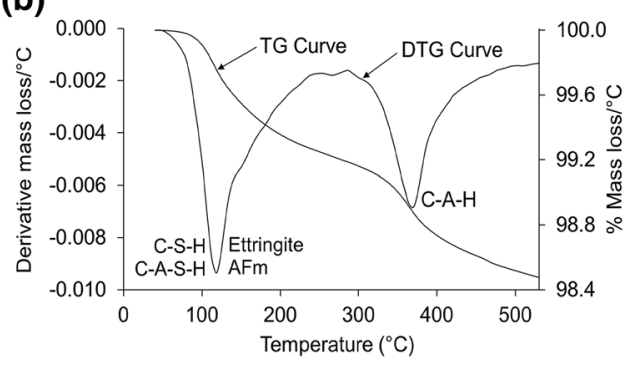

Fig. 3 a Typical TG and DTG curves with identifiable $\mathrm{CH}$ endotherm. b Typical TG and DTG curves with no identifiable $\mathrm{CH}$ endotherm. Note Calcium silicate hydrate $(\mathrm{C}-\mathrm{S}-\mathrm{H})$, Calcium alumino silicate hydrate $(\mathrm{C}-\mathrm{A}-\mathrm{S}-\mathrm{H})$, Calcium aluminate hydrate $(\mathrm{C}-\mathrm{A}-\mathrm{H})$, Aluminate ferrite monosulphate $(\mathrm{AFm})$, Calcium hydroxide $(\mathrm{CH})$.

Table 4 (a) Thermogravimetric analysis of silica fume modified samples at 1, 7 and 28 days of curing. (b) Thermogravimetric analysis of nano silica modified samples at 1,7 and 28 days of curing.

\begin{tabular}{|c|c|c|c|c|c|c|}
\hline & & & $\mathrm{a}$ & & & \\
\hline \multirow[t]{2}{*}{ Mix } & \multicolumn{3}{|c|}{$\mathrm{CH}$ (normalised) } & \multicolumn{3}{|c|}{$\mathrm{CH}$ (residual) } \\
\hline & 1 day & 7 day & 28 day & 1 day & 7 day & 28 day \\
\hline \multicolumn{7}{|c|}{$\mathrm{a}$} \\
\hline $\mathrm{CF}$ & $13.7 \%$ & $11.1 \%$ & $8.3 \%$ & $2.8 \%$ & $2.2 \%$ & $1.7 \%$ \\
\hline $\mathrm{S} 1$ & $13.7 \%$ & $8.8 \%$ & $4.7 \%$ & $2.8 \%$ & $1.8 \%$ & $0.9 \%$ \\
\hline S2 & $11.5 \%$ & $5.2 \%$ & $2.5 \%$ & $2.3 \%$ & $1.0 \%$ & $0.5 \%$ \\
\hline S3 & $6.1 \%$ & $-1.2 \%$ & $-13.8 \%$ & $5.5 \%$ & $4.1 \%$ & $1.6 \%$ \\
\hline S4 & $-0.1 \%$ & $-11.6 \%$ & $-18.9 \%$ & $4.5 \%$ & $2.0 \%$ & $0.6 \%$ \\
\hline \multicolumn{7}{|c|}{$\mathrm{b}$} \\
\hline $\mathrm{CF}$ & $13.7 \%$ & $11.1 \%$ & $8.3 \%$ & $2.8 \%$ & $2.2 \%$ & $1.7 \%$ \\
\hline N1 & $4.7 \%$ & - & - & $0.9 \%$ & - & - \\
\hline $\mathrm{N} 2$ & - & - & - & - & - & - \\
\hline $\mathrm{N} 3$ & $-13.2 \%$ & - & - & $1.7 \%$ & - & - \\
\hline N4 & $-17.9 \%$ & - & - & $0.8 \%$ & - & - \\
\hline
\end{tabular}

$\mathrm{M}_{\mathrm{H}_{2} \mathrm{OCH}}^{\mathrm{S}}$ is mass loss due to the dehydroxylation of portlandite present in the hydrated cement paste. The fraction $\frac{74}{18}$ is used to convert $\mathrm{CH}$ bound water into $\mathrm{CH}$ mass, where 74 is the molar mass of $\mathrm{Ca}(\mathrm{OH})_{2}$ and 18 is the molar mass of $\mathrm{H}_{2} \mathrm{O}$. The fraction $\frac{1}{0.2}$ represents the division of percentage of the OPC content in the sample to normalise the value to per $\mathrm{g}$ of OPC. $\mathrm{M}_{\mathrm{H}_{2} \mathrm{OCH}}^{\mathrm{HL}}$ is mass loss due to the dehydroxylation of the pure $\mathrm{Ca}(\mathrm{OH})_{2}$ present in the raw hydrated lime, as part of the raw $\mathrm{HL}$ was converted to $\mathrm{CaCO}_{3}$ due to its exposure to $\mathrm{CO}_{2}$ present in the atmosphere. The pure $\mathrm{Ca}(\mathrm{OH})_{2}$ content was $81 \%$ of the raw HL sample. $\mathrm{HL}_{\%}$ represnts the percentage of hydrated lime powder added to the sample. TG analysis of silica fume and nano silica modified HV-UFFA pastes cured for 1,7 and 28 days are shown in Table 4a, b, respectively. Negative $\mathrm{CH}$ (normalised) values show that in addition to the $\mathrm{CH}$ released by the OPC, a part of the hydrated lime powder added externally, has also been consumed by the pozzolanic reaction.

XRD analysis of silica fume and nano silica modified HVUFFA pastes cured for 1,7 and 28 days are shown in
Figs. $4 \mathrm{a}$ and $5 \mathrm{a}$, respectively. Their SEM images at 28 days of curing are presented in Figs. $4 \mathrm{~b}$ and $5 \mathrm{~b}$, respectively. Though, $\mathrm{C}-\mathrm{S}-\mathrm{H}$ is considered as the main contributor to the compressive strength of mortar/concrete, but because of its near amorphous nature, it is hard to identify through XRD analysis. Since portlandite is considered as a good indicator of the performance of the hydration/pozzolanic reaction, therefore for the clarity in presentation of the important hydration products, the XRD data is presented from $5^{\circ}$ 2-theta to $25^{\circ}$ 2-theta. Various phases noticed in the XRD patterns were ettringite $(\mathrm{E}), \mathrm{AFm}_{\mathrm{ss}}$ (Aluminate ferrite monosulphate) - most likely a solid solution of hemicarbonate and $\mathrm{OH}^{-}$substituted monosulphate (Matschei et al. 2007) denoted as (A), hemicarbonate $\left(H_{c}\right)$, calcium aluminium iron oxide carbonate hydroxide hydrate $\left(\mathrm{F}_{\mathrm{c}}\right)$, monocarbonate $\left(\mathrm{M}_{\mathrm{c}}\right)$, di-calcium aluminate hydrate $(\mathrm{D})$, mullite $(\mathrm{M})$, portlandite $(\mathrm{P})$, quartz $(\mathrm{Q})$ and calcite $(\mathrm{C})$.

The increase in the pozzolanic reaction, due to the partial replacement of fly ash with silica fume in S1 can be noticed 

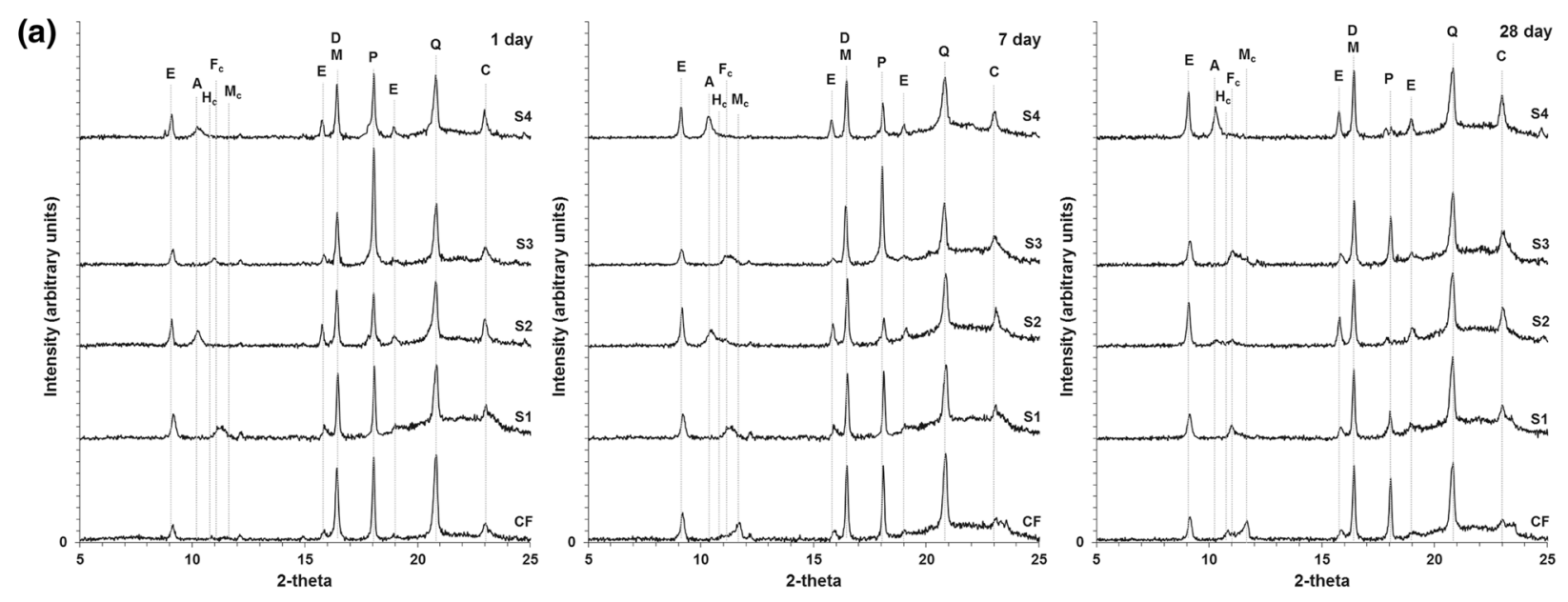

(b)
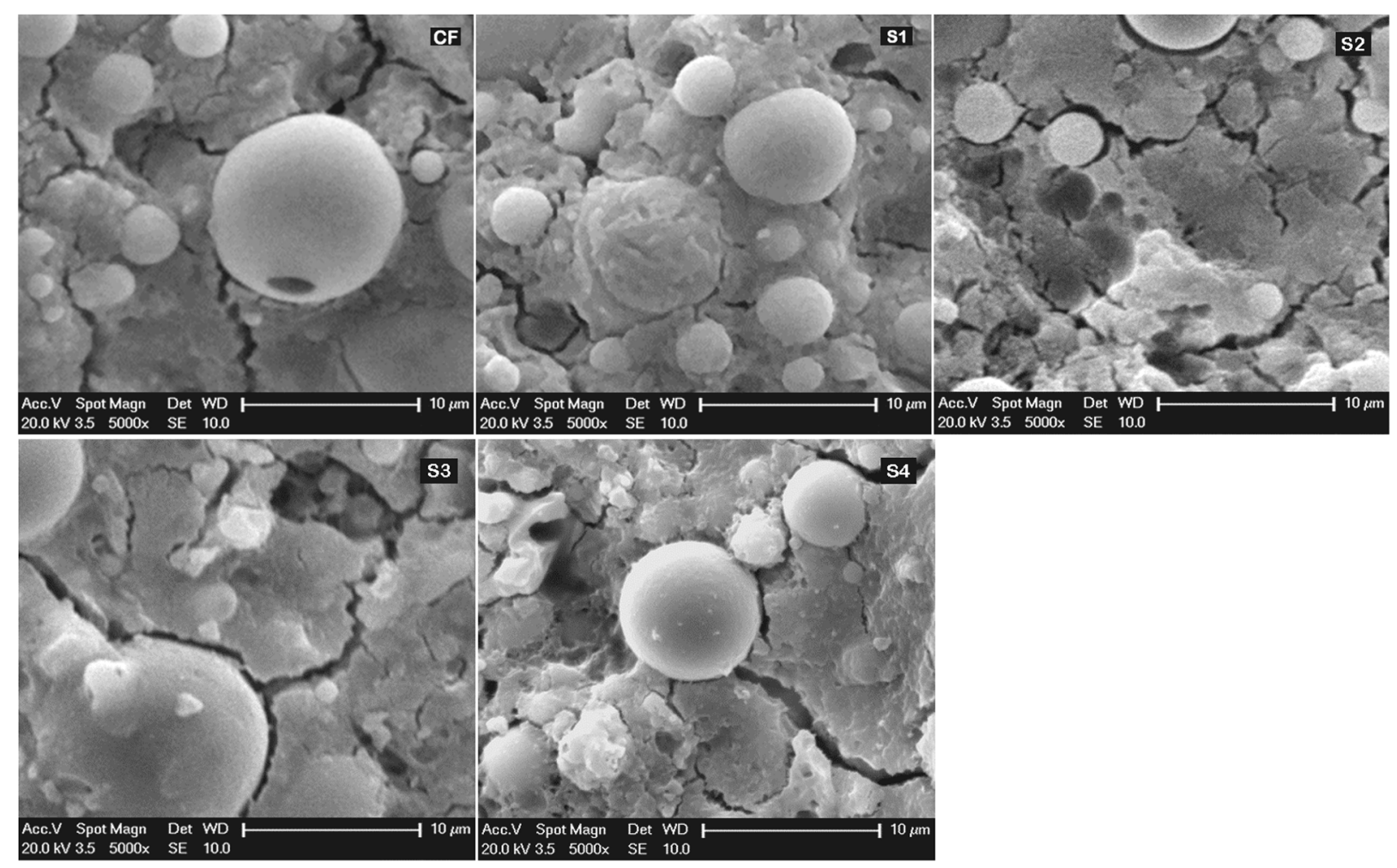

Fig. 4 a XRD spectra of silica fume modified samples at 1, 7 and 28 days of curing. b SEM images of silica fume modified samples at 28 days of curing.

in the reduction of $\mathrm{CH}$ (normalised) value in the TGA data and the portlandite peak in the XRD spectra at both 7 and 28 days of curing. This shows that the portlandite consumption was increased due to the presence of SF which is amorphous in nature and has considerably higher surface area than that of FA. The SEM image of S1 shows a denser $\mathrm{C}-\mathrm{S}-\mathrm{H}$ gel with finer cracks, resulting in a stronger cement matrix than that of $\mathrm{CF}$. This was reflected in the corresponding increase in the compressive strength results of S1 compared to $\mathrm{CF}$.

With the addition of SA in mix S2, there was a small reduction in the $\mathrm{CH}$ (normalised) value at 1 day, which reduced considerably at 7 and 28 days of curing, compared to $\mathrm{S} 1$. Similar observations were seen in the reduction in the portlandite peaks of S2 in the XRD spectra. This increase in the consumption of portlandite is attributed to the accelerating effect of SA on the pozzolanic reaction of the blended mix. The set accelerator used was calcium nitrate and sodium thiocyanate based. Calcium nitrate accelerates the setting time and moderately accelerates hardening whereas sodium thiocyanate accelerates the strength gain (Paillère 1994). As reported by Rettvin and Dalen and cited by Cabrera et al. (Cabrera and Rivera-Villarreal 1999) when calcium nitrate was used in combination with sodium thiocyanate, calcium nitrate started the hydration process earlier which was then hastened by sodium thiocyanate. The SEM image of S2 shows an increase in the density and width of cracks in the cement matrix. The XRD spectra of S2 shows a considerable increase in the intensity of ettringite peaks at 7 and 28 days compared to $\mathrm{S} 1$. The growth of ettringite 


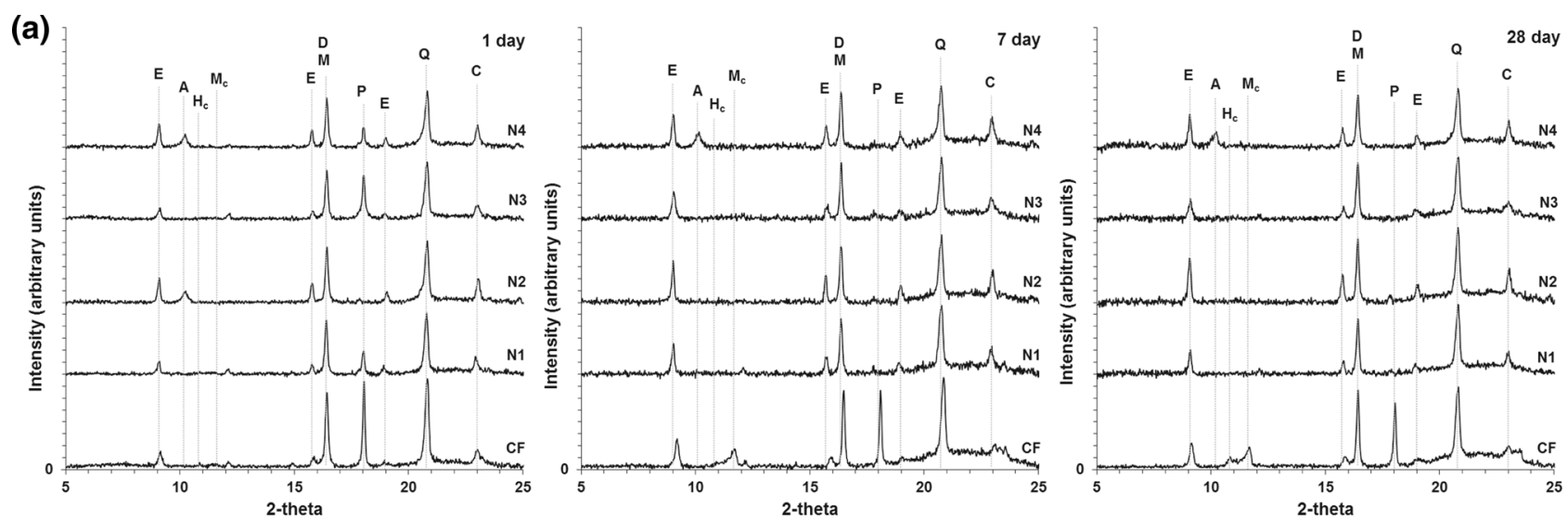

(b)
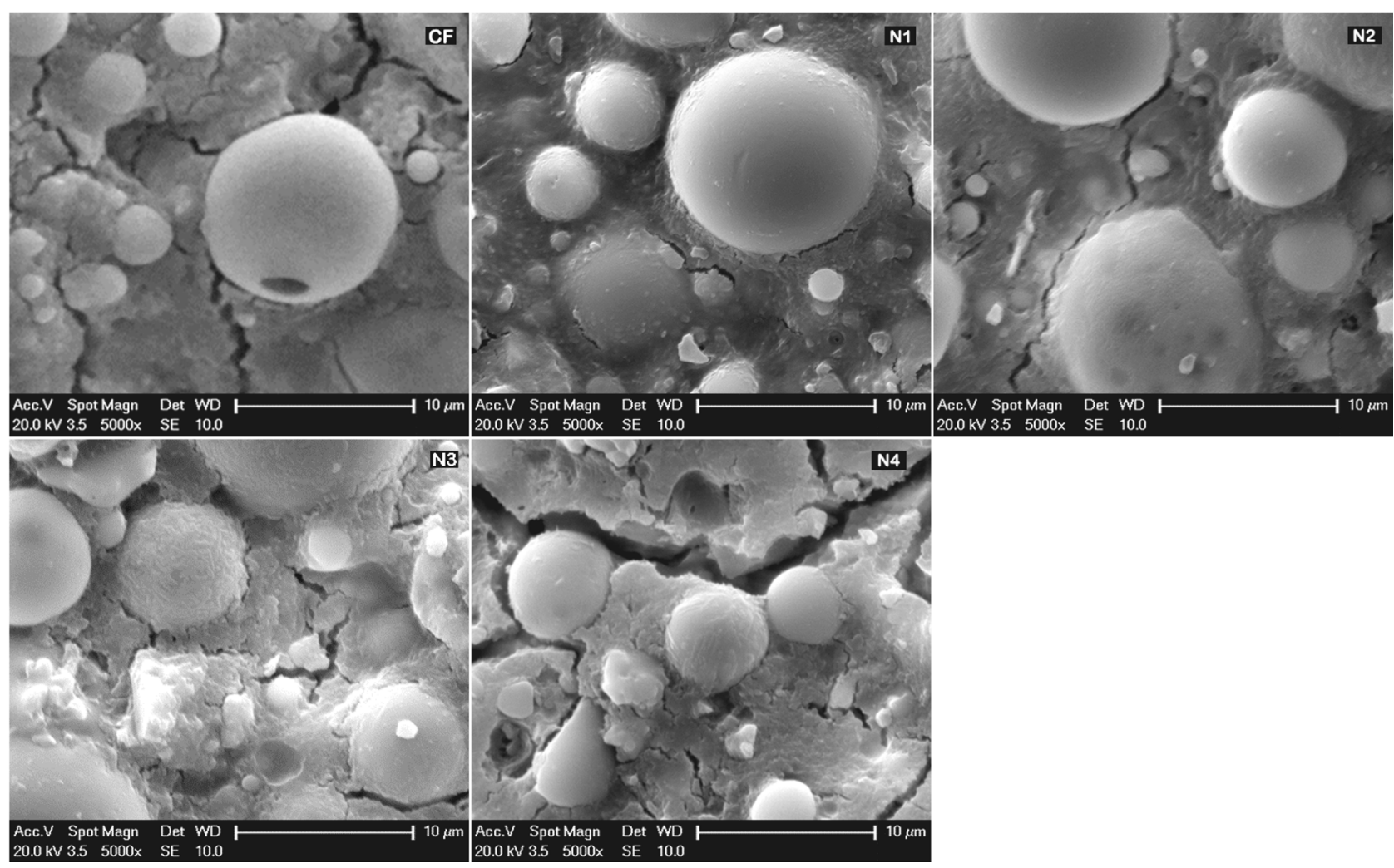

Fig. 5 a XRD spectra of nano silica modified samples at 1,7 and 28 days of curing. b SEM images of nano silica modified samples at 28 days of curing.

crystals in smaller diameter pores refined by silica fume (Zhang and Gjørv 1991), exerts the highest expansive pressure on the pore walls promoting the development of cracks in the cement matrix (Scherer 1999). Though, based on the increase in ettringite content in S2 and the findings of (Scherer 1999), there is a possibility of ettringite being instrumental in the development of cracks, but no ettringite crystal was found within the cracks, when observed through the electron microscope. The addition of SA significantly increases the pore solution concentration of calcium ions $\left(\mathrm{Ca}^{+}, \mathrm{CaOH}^{+}\right)$which induces a high degree of super saturation of portlandite (Nonat 2000) that leads to the increase in disjoining pressure resulting in the development of micro cracks (Beltzung et al. 2001). Beltzung et al. (Beltzung et al. 2001) in their research on the influence of $\mathrm{Ca}(\mathrm{OH})_{2}$ on shrinkage stresses observed that the samples containing high residual portlandite content (portlandite available in pore water after pozzolanic reaction and ettringite formation) showed higher shrinkage stresses resulting from high disjoining pressure, compared to the one having low residual portlandite. They also found that the specimens in which the portlandite produced in the system was progressively consumed during secondary pozzolanic and ettringite reactions, showed very low shrinkage stresses. They concluded that with the use of low alkali cements a significant reduction in the shrinkage stresses originating from the disjoining pressure can be achieved. Tazawa et al. (Tazawa and Miyazawa 1993) and Persson (Persson 1997) studied the relationship of self desiccation effect with the autogenous shrinkage. They reported that the self desiccation (reduction in internal relative humidity) at a particular age of curing increased with the decrease in w/c ratio, resulting in the increase in 
autogenous shrinkage. Tazawa et al. (Tazawa and Miyazawa 1993) also reported that the resultant increase in autogenous shrinkage leads to early age cracking. Therefore, the increase in the development of micro cracks in $\mathrm{S} 2$ could be attributed to the combined effect of disjoining pressure and the self desiccation effect.

By combining silica fume and hydrated lime in mix S3, there was a considerable reduction in the $\mathrm{CH}$ (normalised) values at 1 and 7 days of curing, compared to S1. This shows that the addition of hydrated lime powder significantly increased the pozzolanic reaction of the blended mix. The TGA data and the XRD spectra of S3 show a significant increase in $\mathrm{CH}$ (residual) content and portlandite peak intensity, respectively, at all curing ages, compared to S1. This could be associated with the fact that the additional hydrated lime increased the portlandite content more than that was required to react with the amorphous silica present in SF and FA at 1 and 7 days of curing. At 7 days there was a considerable reduction in the portlandite peak of S3, which further reduced significantly by 28 days, compared to that of $\mathrm{S} 1$, showing an increase in the pozzolanic reaction. Comparing the consumption of the portlandite by S3 with that of S2, at 1,7 and 28 days of curing, S3 showed a higher pozzolanic activity than S2. But the compressive strength results show no difference between $\mathrm{S} 3$ and $\mathrm{S} 2$ at all curing ages. The SEM image of S3 shows wider cracks than that of $\mathrm{S} 2$. This again shows that with the increases in pore solution concentration of $\mathrm{Ca}^{+}$ions, and the decrease in relative internal humidity there is a corresponding increase in the development of micro cracks. The wider the cracks, the deeper they are, indicating that the higher volume of the strength forming $\mathrm{C}-\mathrm{S}-\mathrm{H}$ gel was weakened in S3, thereby, counterbalancing in reducing the strength that was improved by the increase in $\mathrm{C}-\mathrm{S}-\mathrm{H}$ gel.

When both SA and HL were added to the silica fume modified HV-UFFA in Mix S4, there was a significant improvement in the consumption of portlandite at all curing ages as seen from both the TGA data and the XRD spectra. Comparing the TGA data and the XRD spectra of S4 with that of S3, the consumption of portlandite was significantly higher in S4 at all curing ages, due to the combined accelarating effect of the SA and the HL. This increase in the pozzolanic activity was reflected in the compressive strength results of S4 which had the highest strength among all SF modified mixes. This shows that the combined effect of SA and HL provides the best performance in improving the pozzolanic reaction of SF modified HV-UFFA compared to their respective individual effects. The SEM image of S4 shows a further increase in crack width compared to that of $\mathrm{S} 3$. This reinforces our finding that there is a strong correlation of the combined effect of increase in portlandite content and the reduction in relative internal humidity with the resulting increase in crack formation. In-spite of the increase in micro cracking in $\mathrm{S} 4$, the increase in the production of $\mathrm{C}-\mathrm{S}-\mathrm{H}$ gel from the accelerated pozzolanic reaction resulted in counterbalancing the effect of increased cracking, thereby, improving its strength compared to that of $\mathrm{S} 1, \mathrm{~S} 2$ and S3. It is to be noted, that the internal humidity can be increased without altering the w/c ratio and negatively hampering the compressive strength results, with the help of internal curing method as reported by Bentz et al. (2010), though it is not the scope of the present work.

The increase in the pozzolanic reaction, due to the partial replacement of fly ash with silica fume in S1 can be noticed in the reduction of $\mathrm{CH}$ (normalised) value in the TGA data and the portlandite peak in the XRD spectra at both 7 and 28 days of curing.

When the fly ash was partially replaced with $\mathrm{nS}$ in mix N1, there was a significant reduction in the $\mathrm{CH}$ (normalised) value and the corresponding intensity of the portlandite peak at 1 day, compared to CF. At 7 and 28 days of curing no identifiable portlandite content was observed in both the TGA and the XRD data of N1. This shows that with the addition of $\mathrm{nS}$, the consumption of the portlandite content in pozzolanic reaction increased significantly, because of its highly amorphous nature and significantly higher surface area than that of FA. The SEM image of N1 shows a very dense $\mathrm{C}-\mathrm{S}-\mathrm{H}$ gel with a significant reduction in micro cracking, compared to that of $\mathrm{CF}$, resulting in a stronger cement matrix. Since a significant amount of portlandite produced by the OPC was consumed at day 1, and its production at later ages was progressively being consumed due to the accelerated pozzolanic reaction, the resulting microcracking due to the disjoining pressure (Beltzung et al. 2001) were considerably reduced. Moreover, the self desiccation effect of the cement matrix alone had a minimal impact on the propagation of micro-cracking, resulting in a significant reduction in crack formation. The combination effect of increased pozzolanic reaction and highly dense cement matrix, was reflected in the corresponding increase in the compressive strength of N1 compared to $\mathrm{CF}$, at all curing ages. Comparing the effect of silica fume in $\mathrm{S} 1$ to that of nano silica in $\mathrm{N} 1$, nano silica performed considerably better than SF in improving the pozzolanic reaction and densifiying the cement matrix. Though both $\mathrm{SF}$ and $\mathrm{nS}$ are amorphous in nature, the significantly higher surface area of $\mathrm{nS}$ was the main driving force in accelerating the pozzolanic reaction and densifying the cement matrix.

With the addition of SA in mix N2, though the pore solution concentration of $\mathrm{Ca}^{+}$ions from the portlandite increases (Nonat 2000), a considerable reduction in the portlandite content was observed in both the TGA and the XRD data, compared to that of N1. There was no identifiable $\mathrm{CH}$ (residual) content and any noticeable intensity of the portlandite peak in $\mathrm{N} 2$ at all curing ages. This increase in portlandite consumption at 1 day shows that the pozzolanic reaction of $\mathrm{N} 2$ improved considerably with the addition of $\mathrm{SA}$ and the further release of portlandite from OPC at later ages, was progressively being consumed. This considerable improvement in the pozzolanic reaction of $\mathrm{N} 2$ resulted in $30 \%$ increase in its compressive strength, compared to that of $\mathrm{N} 1$ at 1 day of curing. But, the 7 and 28 day strengths decreased by 14 and $11 \%$ respectively. The SEM image of $\mathrm{N} 2$ shows increased micro-cracking than that in N1. Though, the SA considerably increases the pore solution concentration of portlandite, but it was progressively being consumed. 
Therefore, the occurrence of micro cracks was most likely due to the self desiccation effect which increases with the increase in hydration/pozzolanic reaction (Persson 1997). Since, the contribution of fly ash in the production of C-S-H gel is minimal at early age i.e. before 7 days of curing, the skeleton structure of the cement matrix produced primarily from the pozzolanic reaction of nano silica is probably not strong enough to resist internal stresses, resulting in the early devlopment of micro cracks. This weakening of the cement matrix at early age, inspite of the increased pozzolanic reaction results in the reduction of 7 and 28 day compressive strength results of $\mathrm{N} 2$ compared to that of N1.

By adding HL to $\mathrm{nS}$ modified HV-UFFA in mix N3, the intensity of the portlandite peak and the $\mathrm{CH}$ (residual) content, increased considerably compared to that of N1 at 1 day of curing. But when compared with S3, the intensity of its portlandite peak and its $\mathrm{CH}$ (normalised) content was significantly lower. This shows that though the addition of HL significantly increased the portlandite content, the nano silica present in $\mathrm{N} 3$ consumed a large amount of it due to the accelerated pozzolanic reaction at 1 day of curing. There was no identifiable portlandite content observed in both the TGA and the XRD data of N3 at later ages of curing, showing that the remaining portlandite was consumed by the 7 th day and any further release of portlandite from OPC was progessively being consumed. Though the increase in pozzolanic activity resulted in $20 \%$ increase in 1 day strength of N3 compared to N1, the 7 and 28 days showed a strength reduction of 16 and $9 \%$ respectively. The SEM image of N3 showed an increase in crack formation compared to that of N1. Therefore the decrease in 7 and 28 day strengths, inspite of the increase in pozzolanic reaction could be attributed to the the combined effect of high disjoing pressure because of the high portlandite content at 1 day and the self desiccation effect due to the decrease in relative humidity. The strucutral weakness so introduced in the skeleton of the cement matrix at early age negatively impacted its strength development.

When both SA and HL were added together to the nano silica modified HV-UFFA in Mix N4, the consumption of portlandite increased further, as can be seen in the considerable reduction in the $\mathrm{CH}$ (normalised) content and the intensity of the portlandite peak at 1 day of curing, compared to that of N3. This shows that the combined effect of $\mathrm{nS}$, SA and HL provided the highest acceleration in the pozzolanic reaction of HV-UFFA cement composite compared to that of their individual effects. The compressive strength results show a further $23 \%$ increase in 1 day strength of $\mathrm{N} 4$ compared to that of N3. But the 7 and 28 day strengths show a further decrease of 21 and $9 \%$ respectively. The SEM image of N4 shows a further increase in crack width compared to that of N2 and N3. This increase in crack width could be attributed to the combined effect of increased disjoining pressure and decreased internal relative humidity at early age of curing. Since the intensity of the portlandite peak was lower than that of N1 at 1 day of curing, possibly the effect of disjoining pressure was small. But with the increase in the pozzolanic reaction, the self desiccation effect coupled with the increase in disjoining pressure could probably have aggravated the development of micro cracks. The decrease in 7 and 28 day strength of N4 inspite of a significant increase in its pozzolanic reaction, compared to that of $\mathrm{N} 1, \mathrm{~N} 2$ and $\mathrm{N} 3$ shows that the formation of micro cracks at early age is a major deteriorating factor affecting the development of its compressive strength.

\section{Conclusions}

Based on the findings of this research, the following conclusions can be drawn:

(i) Silica fume, when used in conjunction with SA or HL considerably improves the pozzolanic reaction of $\mathrm{HV}$ UFFA cement composite resulting in the improvement of its compressive strength. But, when both SA and HL are used in conjunction with the SF, the combined effect provides the best performance in accelerating the pozzolanic reaction resulting in a significant improvement in its compressive strength.

(ii) Use of silica fume considerably reduces the the development of micro cracks but when it is combined with the SA or HL increases the formation of micro cracks due to the combined effect of disjoining pressure and self desiccation effect. The highest stresses are induced when both the SA and the HL are combined with SF resulting in a significant increase in crack formation. However, this mix presented the best compressive strength because the increase in the production of $\mathrm{C}-\mathrm{S}-\mathrm{H}$ gel from the accelerated pozzolanic reaction resulted in counterbalancing the effect of increased cracking, thereby, improving its compressive strength.

(iii) Nano silica, when used in conjunction with the SA or the HL considerably improves the pozzolanic reaction of HV-UFFA cement composite resulting in the improvement of its 1 day compressive strength. But the formation of micro cracks due the disjoining pressure and self desiccation effect hinders the development of its later age strengths inspite of the increase in pozzolanic reaction. When both SA and HL are used in conjunction with the $\mathrm{nS}$, the combined effect further accelerates the pozzolanic reaction, resulting in considerably improving its 1 day strength. But at later ages their combined effect significantly increases the formation of early age micro cracks resulting in considerably hindering the development of 7 and 28 day strengths, inspite of the increase in pozzolanic reaction.

(iv) Ultra-fine fly ash when combined with nano silica can help in achieving $80 \%$ replacement of cement, having comparable mechanical properties to that of OPC.

However, the limitation of this work is that It does not address the issue of control of micro cracking induced by the self-desiccation effect and disjoining pressure, and will form part of future studies. If the formation of micro cracks are controlled in SA and HL blended HV-UFFA cement 
composites modified with $\mathrm{SF}$ and $\mathrm{nS}$, there is a great potential of tapping the benefits of their accelerated pozzolanic reaction, to further improve their compressive strength results.

Though nano silica presents a great potential in the production of highly environmental friendly cementitious material, its high cost limits its immediate application in the construction industry. But, the recent advances in the research of the production of amorphous nano silica (Lazaro et al. 2012; Lazaro Garcia AA 2014), has paved a way for its cost effective mass production method, which makes its application in construction industry within reach (Quercia and Brouwers 2010).

\section{Acknowledgements}

The authors greatly appreciate the scientific and technical support provided by the RMIT Microscopy \& Microanalysis Facility (RMMF), at RMIT University. The authors would like to thank Cement Australia for providing the material support to carry out this research.

\section{Open Access}

This article is distributed under the terms of the Creative Commons Attribution 4.0 International License (http://creativecommons.org/licenses/by/4.0/), which permits unrestricted use, distribution, and reproduction in any medium, provided you give appropriate credit to the original author(s) and the source, provide a link to the Creative Commons license, and indicate if changes were made.

\section{References}

About Coal Ash-CCP FAQs (2014). American Coal Ash Association; p. Coal Combustion Products-Frequently Asked Questions.

Atis, C. D. (2003). High-volume fly ash concrete with high strength and low drying shrinkage. Journal of Materials in Civil Engineering, 15(2), 153-156.

Barbhuiya, S., Gbagbo, J., Russell, M., \& Basheer, P. (2009). Properties of fly ash concrete modified with hydrated lime and silica fume. Construction and Building Materials, 23(10), 3233-3239.

Beltzung, F., Wittmann, F., \& Holzer, L. (2001). Influence of composition of pore solution on drying shrinkage. Creep, Shrinkage and Durability Mechanics of Concrete and other Quasi-Brittle Materials, edited by Ulm, F-J, Bazant, ZP and Wittmann, FH, Elsevier Science Ltd.

Benhelal, E., Zahedi, G., Shamsaei, E., \& Bahadori, A. (2013). Global strategies and potentials to curb $\mathrm{CO}_{2}$ emissions in cement industry. Journal of Cleaner Production, 51, $142-161$.
Bentz D. P., \& Weiss, W. J. (2011). Internal curing: a 2010 stateof-the-art review: US Department of Commerce, National Institute of Standards and Technology.

Björnström, J., Martinelli, A., Matic, A., Börjesson, L., \& Panas, I. (2004). Accelerating effects of colloidal nanosilica for beneficial calcium-silicate-hydrate formation in cement. Chemical Physics Letters, 392(1), 242-248.

Cabrera, J. G., Rivera-Villarreal, R. (1999). PRO 5: International RILEM Conference on the Role of Admixtures in High Performance Concrete: RILEM.

Chindaprasirt, P., Jaturapitakkul, C., \& Sinsiri, T. (2005). Effect of fly ash fineness on compressive strength and pore size of blended cement paste. Cement \& Concrete Composites, 27(4), 425-428.

De Weerdt, K., Haha, M. B., Le Saout, G., Kjellsen, K. O., Justnes, H., \& Lothenbach, B. (2011). Hydration mechanisms of ternary Portland cements containing limestone powder and fly ash. Cement and Concrete Research, 41(3), 279-291.

Dinakar, P., Babu, K., \& Santhanam, M. (2008). Durability properties of high volume fly ash self compacting concretes. Cement \& Concrete Composites, 30(10), 880-886.

El-Chabib, H., \& Syed, A. (2012). Properties of self-consolidating concrete made with high volumes of supplementary cementitious materials. Journal of Materials in Civil Engineering, 25(11), 1579-1586.

Erdoğdu, K., \& Türker, P. (1998). Effects of fly ash particle size on strength of Portland cement fly ash mortars. Cement and Concrete Research, 28(9), 1217-1222.

Hansen, T. C. (1990). Long-term strength of high fly ash concretes. Cement and Concrete Research, 20(2), 193-196.

Heidrich C., Feuerborn H. -J., \& Weir A. (2013). Coal Combustion Products: a Global Perspective. WOCA.

Hill, R. L. (1994). The study of hydration of fly ash in the presence of calcium nitrate and calcium formate, University of North Texas, Denton, TX.

Hou, P., Wang, K., Qian, J., Kawashima, S., Kong, D., \& Shah, S. P. (2012). Effects of colloidal nanoSiO 2 on fly ash hydration. Cement \& Concrete Composites, 34(10), 1095-1103.

Huang, C.-H., Lin, S.-K., Chang, C.-S., \& Chen, H.-J. (2013). Mix proportions and mechanical properties of concrete containing very high-volume of Class F fly ash. Construction and Building Materials, 46, 71-78.

Islam, M. S. (2014). Comparison of ASR mitigation methodologies. International Journal of Concrete Structures and Materials, 8(4), 315-326.

Jayakumar, M., \& Abdullahi, M. S. (2011). Experimental study on sustainable concrete with the mixture of low calcium fly ash and lime as a partial replacement of cement. Advanced Materials Research, 250, 307-312.

Jo, B.-W., Kim, C.-H., Tae, G.-H., \& Park, J.-B. (2007). Characteristics of cement mortar with nano- $\mathrm{SiO}_{2}$ particles. Construction and Building Materials, 21(6), 1351-1355.

Kasai, Y., Matsui, I., Fukushima, Y., \& Kamohara, H. (1983). Air permeability and carbonation of blended cement mortars. ACI Special Publication, p. 79. 
Lazaro, A., Brouwers, H., Quercia, G., \& Geus, J. (2012). The properties of amorphous nano-silica synthesized by the dissolution of olivine. Chemical Engineering Journal, 211, 112-121.

Lazaro Garcia, A. A., Quercia, G. G., \& Brouwers, H. (2014). Synthesis of nano-silica at low temperatures and its application in concrete. In Proceedings of the International Conference Non-Traditional Cement \& Concrete V, June 16-19, 2014, Brno, Czech Republic.

Li, G., \& Wu, X. (2005). Influence of fly ash and its mean particle size on certain engineering properties of cement composite mortars. Cement and Concrete Research, 35(6), $1128-1134$.

Liu, M. (2010). Self-compacting concrete with different levels of pulverized fuel ash. Construction and Building Materials, 24(7), 1245-1252.

Malhotra, V. M., Mehta, P. K., \& Development SCMfS. (2002). High-performance, high-volume fly ash concrete: materials, mixture proportioning, properties, construction practice, and case histories: Suppementary Cementing Materials for Sustainable Development.

Matschei, T., Lothenbach, B., \& Glasser, F. (2007). The AFm phase in Portland cement. Cement and Concrete Research, 37(2), 118-130.

Mehta, P. K. (1986). Concrete. Structure, properties and materials

Nagataki, S., \& Ohga, H. (1992). Combined effect of carbonation and chloride on corrosion of reinforcement in fly ash concrete. ACI Special Publication.

Nakarai, K., \& Ishida, T. (2009). Numerical evaluation of influence of pozzolanic materials on shrinkage base on moisture state and pore structure. In Creep, Shrinkage and Durability Mechanics of Concrete and Concrete Structures, Two Volume Set: Proceedings of the CONCREEP 8 conference, Ise-Shima, Japan. CRC Press.

Nonat, A. (2000). PRO 13: 2nd International RILEM Symposium on Hydration and Setting-Why Does Cement Set? An interdisciplinary approach: RILEM Publications.

Paillère, A. M. (1994). Application of admixtures in concrete: CRC Press.

Paya, J., Monzo, J., Peris-Mora, E., Borrachero, M., Tercero, R., \& Pinillos, C. (1995). Early-strength development of Portland cement mortars containing air classified fly ashes. Cement and Concrete Research, 25(2), 449-456.

Pepper, L., \& Mather, B. (1959). Effectiveness of mineral admixtures in preventing excessive expansion of concrete due to alkali-aggregate reaction. American Soc Testing \& Materials Proc.

Persson, B. (1997). Self-desiccation and its importance in concrete technology. Materials and Structures, 30(5), 293-305.

Quercia, G., \& Brouwers, H. (2010). Application of nano-silica $(\mathrm{nS})$ in concrete mixtures. In 8 th fib PhD symposium in Kgs Lyngby, Denmark, 2010 (pp. 431-436).
Rashad, A. M. (2014). Seleem HE-DH, Shaheen AF. Effect of silica fume and slag on compressive strength and abrasion resistance of HVFA concrete. International Journal of Concrete. Structures and Materials, 8(1), 69-81.

Reis, R., \& Camões, A. (2011). Eco-efficient ternary mixtures incorporating fly ash and metakaolin. In International Conference on Sustainability of Constructions - Towards a Better Built Environment. Proceedings of the Final Conference of COST Action C25, Feb 3-5, 2011, University of Innsbruck, Austria.

Şahmaran, M., Yaman, İ. Ö., \& Tokyay, M. (2009). Transport and mechanical properties of self consolidating concrete with high volume fly ash. Cement \& Concrete Composites, 31(2), 99-106.

Sata, V., Jaturapitakkul, C., \& Kiattikomol, K. (2007). Influence of pozzolan from various by-product materials on mechanical properties of high-strength concrete. Construction and Building Materials, 21(7), 1589-1598.

Scherer, G. W. (1999). Crystallization in pores. Cement and Concrete Research, 29(8), 1347-1358.

Sellevold E, Radjy F (1983). Condensed silica fume (microsilica) in concrete: water demand and strength development. ACI Special Publication, p. 79.

Shaikh, F., Supit, S., \& Sarker, P. (2014). A study on the effect of nano silica on compressive strength of high volume fly ash mortars and concretes. Materials and Design, 60, 433-442.

Singh, L. P., Goel, A., Bhattachharyya, S. K., Ahalawat, S., Sharma, U., \& Mishra, G. (2015). Effect of Morphology and Dispersibility of Silica Nanoparticles on the Mechanical Behaviour of Cement Mortar. International Journal of Concrete Structures and Materials, 9, 1-11.

Sivasundaram, V., Carette, G., \& Malhotra, V. (1990). Longterm strength development of high-volume fly ash concrete. Cement \& Concrete Composites, 12(4), 263-270.

Tazawa, E., \& Miyazawa, S. (1993). Autogenous shrinkage of concrete and its importance in concrete technology. In RILEM Proceedings (p. 159). Chapman \& Hall.

Turanli, L., Uzal, B., \& Bektas, F. (2005). Effect of large amounts of natural pozzolan addition on properties of blended cements. Cement and Concrete Research, 35(6), 1106-1111.

Wei, X., Zhu, H., Li, G., Zhang, C., \& Xiao, L. (2007). Properties of high volume fly ash concrete compensated by metakaolin or silica fume. Journal of Wuhan University of Technology-Mater Science, 22(4), 728-732.

Zhang, M.-H., \& Gjørv, O. E. (1991). Effect of silica fume on pore structure and chloride diffusivity of low parosity cement pastes. Cement and Concrete Research, 21(6), 1006-1014.

Zhang, M.-H., \& Islam, J. (2012). Use of nano-silica to reduce setting time and increase early strength of concretes with high volumes of fly ash or slag. Construction and Building Materials, 29, 573-580. 